\title{
Heterotrophic utilisation of a labelled algal extract in water samples from a subtidal reef
}

\author{
M. H. Schleyer \\ Oceanographic Research Institute, P. O. Box 10712, Marine Parade 4056, Durban, South Africa
}

\begin{abstract}
The major primary food source found on a typical Natal reef in South Africa is macrophytic detritus, largely of marine origin. Rapid release of soluble contents of the detritus is caused by vigorous surf action on the reefs; this was demonstrated experimentally. Free-living bacteria are the most common microorganism found in the water column and they appear to be heterotrophically the most active. It was thus postulated that they must use this dissolved substrate; if uniformly labelled, it should provide a suitable tracer for studying their heterotrophic activity. A salt-tolerant Chlorella sp. was cultured with $\mathrm{NaH}^{14} \mathrm{CO}_{3}$ for sufficient duration to permit uniform labelling and its soluble cell contents and excretory products were extracted for this purpose. Extracts of specific activity $0.67 \mu \mathrm{Ci}$ $\mathrm{mg}^{-1}$ organic carbon and $58.07 \mu \mathrm{Ci} \mathrm{mg}^{-1}$ organic carbon were prepared and used in heterotrophic potential experiments. The results are evaluated and compared with results of glucose uptake measured in parallel experiments and during previous seasonal sampling. The results indicate that microbial heterotrophic activity exceeded primary production by phytoplankton in the study area
\end{abstract}

\section{INTRODUCTION}

A study on a nearshore subtidal reef in Natal, South Africa (Schleyer, 1980a, 1981), established that the major primary food source is seaweed, most of which enters the detritus food chain. Terrestrial macrophytic material is also introduced to the marine environment by rivers swollen by summer rains, making a further contribution to the detrital pool. The combined material accumulates in eddies adjacent to reefs such as the one studied and disintegrates rapidly in the rough surf. Soluble contents leach rapidly from it, a fact demonstrated in an experiment reported here in which the isotope released from sand-churned, labelled seaweed was measured. Free-living bacteria are the most common microorganism found in the water column; heterotrophically they appear to be the most active. It was thus postulated that they must use this dissolved substrate and, if uniformly labelled, the substrate should provide a suitable tracer to study their activity in heterotrophic potential experiments. Preliminary work using a labelled algal extract (LAE) for this purpose showed promise (Schleyer, 1980a) and the results of further experiments are presented in this paper.

\section{MATERIALS AND METHODS}

\section{Study area}

The reef studied is situated in front of the Oceanographic Research Institute (ORI), Durban, and is known as ORI Reef. It consists of sandstone, measures approximately $80 \times 20 \mathrm{~m}$ and runs straight out to sea. It is subjected to heavy and continuous surf action and only at some spring low tides is a portion of the reef exposed. At high tide the reef is covered by 1 to $1.8 \mathrm{~m}$ of water and its top is usually about $1 \mathrm{~m}$ above the surrounding sand. Water conditions in the area are subtropical with an annual mean temperature of $21.8^{\circ} \mathrm{C}(1957-1974)$; mean salinity is $35.2 \%$. ORI Reef is densely populated by the mussel Perna perna and is also inhabited by other suspension feeders, mainly the oyster Saccostrea margaritacea and the tunicate Pyura stolonifera, all of which are typical of this habitat in Natal. P. perna is capable of filtering particles as small as the free-living bacteria mentioned above (Schleyer, 1980b; Berry and Schleyer, 1983). Thus these bacteria probably constitute an important link in the food chain. 


\section{Demonstration of the release of dissolved organic carbon (DOC) from sand-churned seaweed}

Freshly collected tufts of Halimeda cuneata and Jania rubens were incubated for one $24 \mathrm{~h}$ cycle (6L : $12 \mathrm{D}: 6 \mathrm{~L}$ ) at $22^{\circ} \mathrm{C}$ in sterile-filtered seawater containing $1 \mu \mathrm{Ci} \mathrm{ml} \mathrm{ml}^{-1} \mathrm{NaH}^{14} \mathrm{CO}_{3}$. Natural daylight from an east-facing window was used for incubation, after which the seaweeds were rinsed twice for $15 \mathrm{~min}$ in sterile-filtered seawater. They were divided in half and each half was separately placed in a $1 \mathrm{I}$ Erlenmyer flask containing $75 \mathrm{ml}$ of washed, boiled beach sand and $200 \mathrm{ml}$ sterile-filtered seawater. One in each pair of flasks was agitated for $2 \mathrm{~s}$ in every $10 \mathrm{~s}$ with a good shake and vigorous swirl to simulate churning surf. The other was retained as a control and was only gently agitated to ensure mixing before the removal of $1 \mathrm{ml}$ subsamples of seawater. These were withdrawn periodicaliy to monitor the release of label as a mcasure of DOC release from the seaweed by radio-active counting in $10 \mathrm{ml}$ Insta-gel. Radio-active counts for early work described in this paper were performed using a Packard Model 3380 liquid scintillation counter fitted with automatic external standardisation and an Absolute Analyser Model 544 for conversion of cpm to dpm. This was later replaced with a similarly equipped LKB Model 1211 Minibeta liquid scintillation counter

These 2 seaweeds were chosen for the study since their thalli are tough and they are persistent in debris adjacent to the ORI Reef. If DOC release is demonstrable in these forms, it follows that it would be more evident in softer, more delicate species.

\section{Production of labelled algal extract (LAE)}

Production and use of LAE was similar to the methods described by Schleyer (1980a). A salt-tolerant Chlorella sp., obtained from an outdoor saltwater pond and adapted to continuous light irradiation of 2000 lux, was incubated at ambient temperature in a boro-silicate bottle at a dilution of $1: 2$ with $2 \%$ Alga-gro seawater medium (Carolina Biological Supply Company, Burlington, North Carolina, USA). Alga-gro is a nitrate and phosphate enriched algal growth medium free of carbonates and bicarbonates. At this, the normal application of Alga-gro (James, 1974), the high lipid levels stored by Chlorella in nitrogen-deficient media (Spoehr and Milner, 1949; Strickland, 1960; Round, 1965) were not expected. $\mathrm{NaH}^{14} \mathrm{CO}_{3}$ of high specific activity $\left(680 \mu \mathrm{Ci} \mathrm{mg}^{-1}\right)$ was added to the culture at a final concentration of $10 \mu \mathrm{Ci} \mathrm{ml} \mathrm{ml}^{-1}$ at the start of incubation. The labelled bicarbonate is diluted by carbonates and bicarbonates in seawater so the absence of these ions in the Alga-gro is considered an advantage. After incubation for $3 \mathrm{~d}$ to permit uniform labelling of the Chlorella cells, the culture was centrifuged and the pellet was reconstituted in a small quantity of sterilefiltered seawater. To it was added the residual particulate fraction from the incubation medium. This was collected on a $0.2 \mu \mathrm{m}$ pore-size polycarbonate membrane filter and carefully removed with a clean razor blade by gently scraping it off after placing the filter on a flat sheet of clean glass. Algae excrete a wide range of organic substances (Hellebust, 1974); excreted $\mathrm{DO}^{14} \mathrm{C}$ left in the medium was extracted by successively passing it through a SEP-PAK $\mathrm{C}_{18}$ chromatographic cartridge (Waters Associates Inc., Milford, Massachusetts 01757, USA). The organic material was eluted with $2 \mathrm{ml}$ of methanol and the process was repeated 5 times to ensure maximum extraction of the $\mathrm{DO}^{14} \mathrm{C}$. The methanol was evaporated in a hot water bath at $45^{\circ} \mathrm{C}$ and the dissolved organic material was also added to the reconstituted pellet. This was sonicated in an ice bath at 100 to $150 \mathrm{~W}$ for $20 \mathrm{~min}$ using an Ultrasonic SP914 probe sonicator and then repeatedly frozen and thawed to achieve maximum disruption of cellular components. Finally it was centrifuged at $1800 \mathrm{G}$ for $30 \mathrm{~min}$ and the remaining ${ }^{14} \mathrm{CO}_{2}$ was flushed out by bubbling ${ }^{12} \mathrm{CO}_{2}$ through the supernatant which was then membrane-filtered $(0.2 \mu \mathrm{m}$ pore size) and frozen in a sterile container until use. DOC content of the resultant LAE was analysed using a Beckman Model 915A Carbon Analyser. A specific activity for the LAE of $58.07 \mu \mathrm{Ci} \mathrm{mg}{ }^{-1}$ organic carbon was established by liquid scintillation counting, making it satisfactory as a heavily-labelled tracer according to the criteria of Wiebe and Smith (1977).

\section{Measurement of heterotrophic potential}

The method of Hobbie and Crawford (1969), adapted from the original method of Parsons and Strickland (1962), was employed with a few modifications (Schleyer, 1980a) to measure heterotrophic potential using tracer quantities of D-[U- $\left.{ }^{14} \mathrm{C}\right]$ glucose and LAE in parallel experiments. Twenty-five ml seawater samples from ORI Reef were inoculated to 5 final concentrations of between 19.3 and $96.6 \mu \mathrm{g} \mathrm{Cl}^{-1} \mathrm{LAE}$ or 0.645 and $3.226 \mu \mathrm{g} \mathrm{l}^{-1}$ glucose in sealed, heat-sterilized $125 \mathrm{ml}$ Erlenmyer flasks. These were incubated for $1 \mathrm{~h}$ in the dark at sea temperature; the assimilated particulate and respired fractions of ${ }^{14} \mathrm{C}$ were then separately collected for counting. Sterile-filtered seawater samples with added labelled substrate were used as controls for background counts and for monitoring sterility of the substrates. At the end of incubation, addition of $1 \mathrm{ml}$ of $2 \mathrm{~N} \mathrm{H}_{3} \mathrm{PO}_{4}$ to stop biological activity and release 
respired (in controls residual) ${ }^{14} \mathrm{CO}_{2}$ prior to filtration caused precipitation of a component of the LAE; maximum filtrate counts were found in the controls in which no LAE was assimilated by bacteria. Therefore, filtration was performed immediately after incubation without fixation or, when large numbers of samples were handled, biological activity was effectively reduced by sample dilution with sterile-filtered seawater. Particulate material in each sample was filtered onto a $0.2 \mu \mathrm{m}$ pore-size polycarbonate filter which was then digested by $100 \mu \mathrm{l}$ phenylethylamine introduced into a capless vial suspended in each Erlenmyer flask. After $1 \mathrm{~h}$ the contents of the vials were separately flushed into scintillation vials with three $3.3 \mathrm{ml}$ aliquots of Instagel for counting. The efficiency of this system was calibrated for correction of the results by collection of the labelled gas released by acid from small amounts of $\mathrm{NaH}^{14} \mathrm{CO}_{3}$. Linear regressions of Hanes-Woolf transformations (Segel, 1975) of the data for total uptake according to Michaelis-Menten enzyme kinetics (Wright and Hobbie, 1965, 1966) provided values for: $V_{\max }$, the theoretical maximum rate of uptake of the substrate; $\mathrm{K}+\mathrm{S}$, the Michaelis-Menten transport constant and natural substrate concentration; and $T$, the turnover time of the substrate. These experiments were performed at all seasons.

\section{RESULTS}

DO ${ }^{14} \mathrm{C}$ release from labelled seaweeds which were artificially sand-churned was 2.5 to 3 times faster than from controls which were gently agitated (Fig. 1). The release from Jania rubens was greater and by the end of the experiment the sand-churned fronds were breaking into fragments. The sand-churned lobes of Halimeda cuneata were not as severely damaged; they did not disintegrate but were well polished and were becoming pitted.

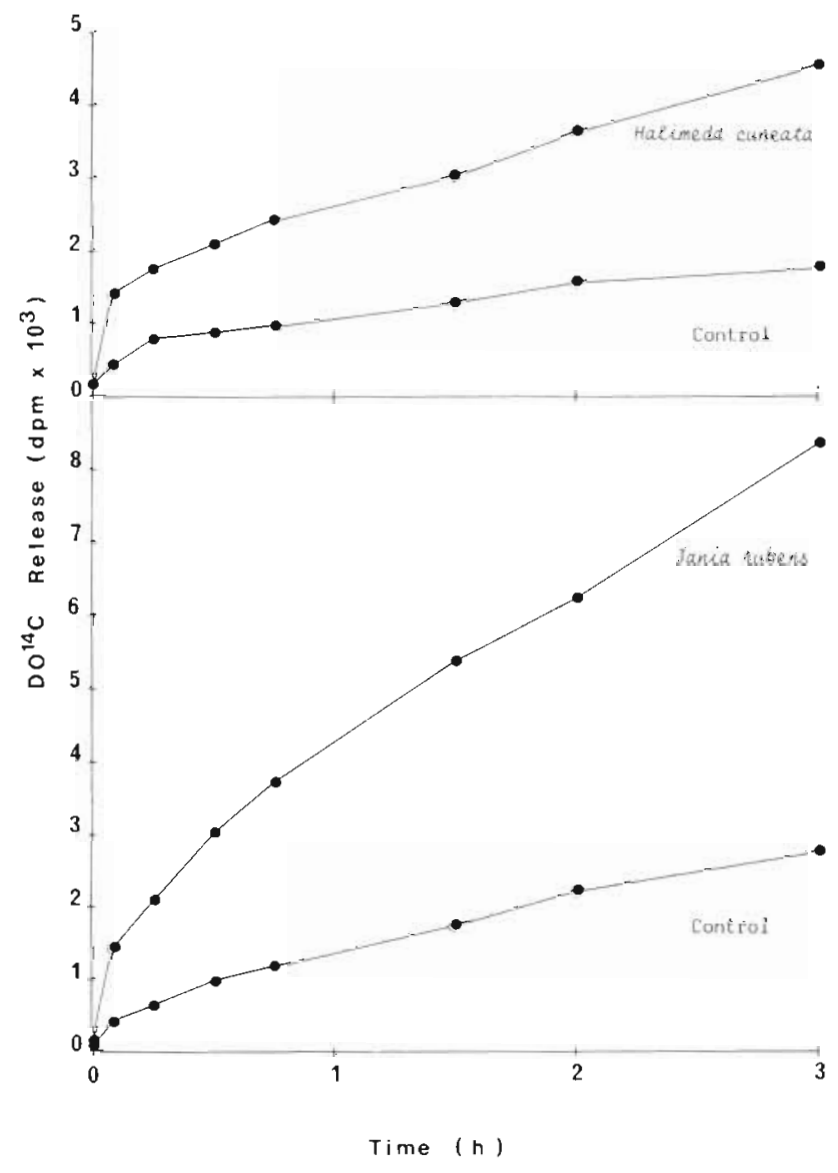

Fig. 1. Release of $\mathrm{DO}^{14} \mathrm{C}$ from labelled, sand-churned seaweed, measured in $1 \mathrm{ml}$ seawater subsamples

The uptake of labelled glucose and LAE measured in parallel heterotrophic potential experiments provided the mean seasonal results presented in Table 1. Previously published results (Schleyer, 1980a) on preliminary uptake work using labelled glucose and a similarly prepared LAE of lower specific activity are included for comparison. Data only of significance at

Table 1. Mean seasonal results of the uptake of labelled glucose and LAE measured in parallel heterotrophic potential experiments. Values are presented for $V_{\max }$, the theoretical maximum attainable rate of uptake, $\mathrm{K}+\mathrm{S}$, the Michaelis-Menten transport constant + natural substrate concentration and $T$, the turnover time of the substrate. Values for glucose in parentheses are seasonal results from a previous years's fortnightly results (Summer 1978-Autumn 1979)

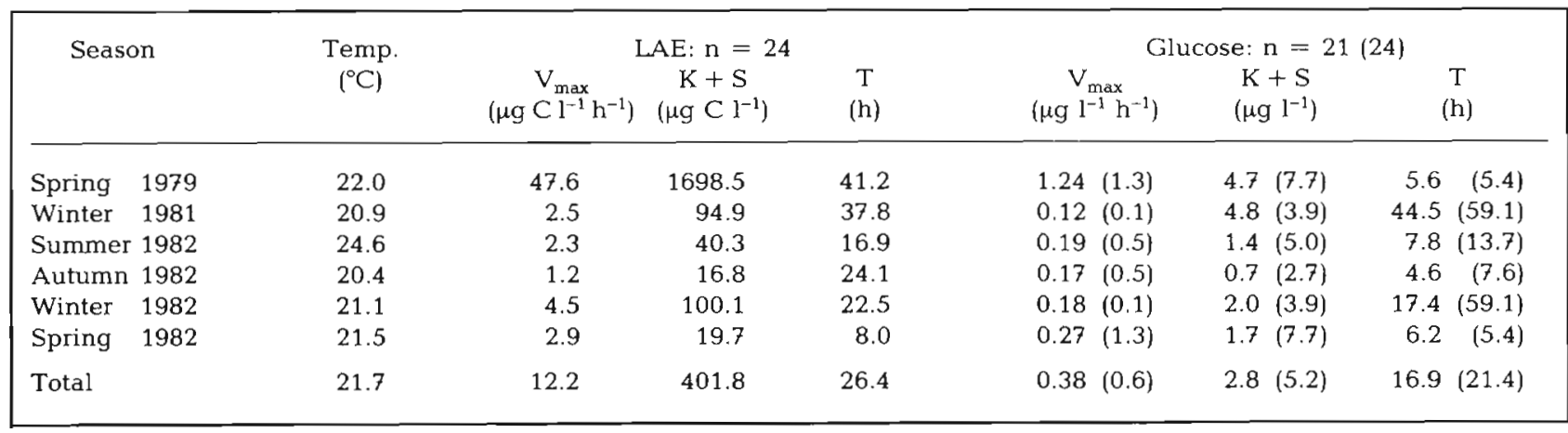


the $95 \%$ level or better when tested with the $\mathrm{F}$ ratio test (Fisher and Yates, 1963) were used in the compilation of the table. Nine \% of the results for LAE and $22 \%$ for glucose were rejected as being not significant. Regressions from $55 \%$ of the LAE results had F ratios greater than 4 times the critical $F$ value at the $95 \%$ level of confidence, indicating that they were predictive as well as significant (Draper and Smith, 1966). Values for uptake of LAE were consistently higher than those for glucose.

The preliminary work performed in spring 1979 yielded higher values for both substrates, and values for glucose uptake measured fortnightly in the previous year (Schleyer, 1981) were also elevated (figures in parentheses in Table 1). The data for $V_{\max }$ from which Table 1 is derived are presented in Fig. 2 where the difference between the results obtained before and after 1980 is clearly portrayed. During 1980 extensive and prolonged dredging of a local river, the Mgeni, was initiated (indicated in Fig. 2 by an arrow), adversely increasing turbidity in the sea by a considerable amount and probably influencing the results.

Aspects of the work with results similar to those fully reported and discussed by Schleyer (1980) will not be repeated here, e.g. the amount of substrate respired, being $\sim 22 \%$ of the glucose and $\sim 1.5 \%$ of the LAE taken up.

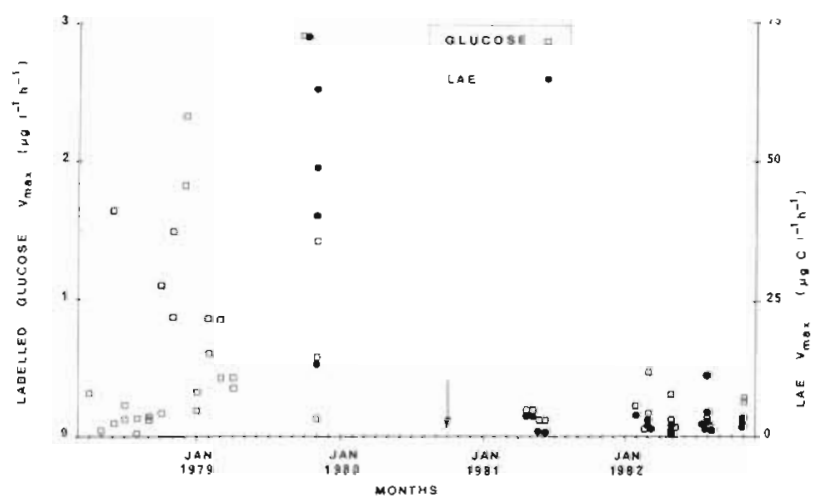

Fig. 2. $V_{\max }$ values of labelled glucose and LAE from which Table 1 is derived. Prior to 1980 high values were obtained for uptake of both substrates which were not found in later work. During 1980 extensive dredging of a local river, the Mgeni, was initiated (indicated by arrow). This increased the turbidity in the sea considerably and probably influenced the results

\section{DISCUSSION}

Use of LAE to trace microbial heterotrophy on the ORI Reef is only valid if seaweed-derived DOC is in fact released as a natural food resource. Although such release is considered an obvious consequence of damage to seaweed (Wangersky, 1978), it was nevertheless demonstrated in the experiment in which robust seaweeds from the reef were artificially sand-churned (Fig. 1). The release would undoubtedly have been greater with softer algal species.

Since seaweed appears to be the main source of the natural dissolved substrate, LAE derived from this source would be most suitable for uptake studies. Careful selection of the alga for this purpose would be important as the biochemistry of the chosen species should be typical of seaweeds which contribute to debris on Natal reefs. Green and red algae are the most common seaweeds on the Natal coast (Jackson, 1976) and besides the composition of their pigments, which comprise only a small proportion of their mass (Strickland, 1965), the major difference between the 2 groups is in their storage products - starch and floridean starch, respectively (Boney, 1966; Lewin, 1974). Both of these are $\alpha-(1,4)$-linked glucans and are readily hydrolysed by amylases (Craigie, 1974). They consist largely of amylopectin, but floridean starch also contains a small number of $\alpha$ - $(1,3)$-linkages and chlorophyte starch a small amount of amylose (Boney, 1966; Craigie, 1974). The 2 algal groups are biochemically similar in other respects except in their composition of structural polysaccharides which are of no significance in the production of a soluble LAE. Thus a suitable representative from either should satisfy the biochemical criteria required for LAE production. The only exception to the above is the family Ulvaceae, members of which occur on the reef but would be unsuitable as they atypically produce sucrose as a storage product (Boney, 1966; Percival and Smestad, 1972).

Uniformity in labelling is another criterion essential for successful use of LAE in the present work. Since seaweeds are differentiated with meristematic regions this would be difficult to achieve, except by incubating for a long period to permit considerable growth. Attempts to do this with suitable seaweeds proved unsuccessful (Schleyer, 1980b) and it was decided that the problem of uniformity in labelling could largely be surmounted by using a healthy unicellular phytoplankton culture in which all the cells would be equally active. A natural assemblage of ORI Reef prymnesiophyte flagellates and diatoms was considered as this alternative. Parsons et al. (1961) found a remarkable similarity in the proportional content of protein, carbohydrate, fat and even the principal monosaccharides and amino acids in 11 healthy metabolising phytoplankton species. These were selected from diverse algal families, including the chlorophytes, prymnesiophytes and diatoms. However, the storage product of the latter 2 is the $\beta-(1,3)$-glucan, chrysolaminarin (Lewin, 1974; Sieburth, 1979), and never starch (Boney, 1966). Thus their biochemistry 
cannot be considered representative of that of Natal reef seaweeds and they too were rejected.

Finally the well-known phytoplankter, Chlorella, was chosen and labelled with considerable success. High lipid levels are stored by many algae when grown in nitrogen-deficient media (Round, 1965) and Chlorella is no exception (Spoehr and Milner, 1949; Strickland, 1960; Round, 1965). However, it appears to be biochemically typical of the chlorophytes when cultured in non-deficient media (Milner, 1961) and care was taken to provide it with optimum growth conditions. LAE considered to be analogous to seaweed-derived DOC was thus produced.

Schleyer (1980a) presented evidence that the $V_{\max }$ values for LAE uptake provide an approximate measure of the bulk of microbial heterotrophic production in ORI Reef water samples. In this evaluation of the preliminary work, uptake of the Chlorella LAE was linear, even though the LAE was a complex mixed substrate taken up by morphologically different bacteria which possibly had different uptake rates (Schleyer, 1980a). A similar finding in the present work is indicated by the high statistical validity of the LAE results. Using the same technique, Bell (1980) found the uptake of labelled phytoplanktonic extracellular products was also linear according to enzyme kinetics. Such extracellular products generally consist predominantly of a few compounds of low molecular weight (Hellebust, 1965, 1974), and Bell suggested that linearity of uptake of the tracer indicated that an identical substrate was supporting natural heterotrophic activity in situ. His argument was that a bacterial interaction with the substrate had developed by adaptation and enzyme induction in the natural environment and natural heterotrophic activity was measured using the labelled extracellular products. Bell's interpretation of non-linear uptake or of regressions with zero slope would be that the tracer was of minimal importance to the bacteria relative to their utilization of other nutrient sources. This he demonstrated by adapting the natural bacteria to a foreign substrate before incubation with the algal extracellular products or by incubation with extracellular products from a foreign source. In the present and previous work, uptake of the LAE commenced and continued without fluctuation from the start of the short incubation period which was of insufficient duration to permit adaptation to the substrate. Thus the linearity of LAE uptake suggests that it was representative of uptake of the complex natural substrate to which the bacterial population on ORI Reef had already adapted, and the measured rate of uptake was an average for different rates which may have occurred within the population.

Uptake of LAE was considerably greater than that of ${ }^{14} \mathrm{C}$ glucose (Table 1 ) which merely provides an index of heterotrophic activity. Although increase or decrease in the uptake of one of these was generally accompanied by a similar change in the uptake of the other, there was no significant mathematical relationship between the rates of uptake of the 2 labelled substrates. This was true of both Chlorella extracts despite the fact that they were separately produced and used at entirely different concentrations.

Environmental disturbance seems to have influenced the results collected after 1980 (Fig. 2) but it is unlikely that increased turbidity would have affected the activity of microbial heterotrophs to the extent to which it appears depressed. A more likely suggestion is that the turbidity impaired primary production by seaweeds, thus reducing the major source of autochthonous detritus on reefs in the study area.

Even though the measurements taken after 1980 were probably depressed (Fig. 2), a mean daily value of $293 \mu \mathrm{g} \mathrm{Cl}^{-1} \mathrm{~d}^{-1}$ calculated from the $V_{\max }$ of LAE exceeds that of phytoplanktonic primary production measured in the study area in previous years $(\bar{x}=$ $154 \mu \mathrm{g} \mathrm{Cl}^{-1} \mathrm{~d}^{-1}$; Schleyer, 1981). The results for LAE also show that assimilable DOM is turning over in a relatively short time $(\overline{\mathrm{x}} \mathrm{T}=26.4 \mathrm{~h})$. This supports earlier findings that microbial heterotrophs are more important than phytoplankton in energy transfer to suspension-feeders on Natal reefs. Much of the detritus on which the microheterotrophs depend becomes available to them as DOM in accordance with a model, based largely on work on coastal ecosystems, in which half or more of the primary production is channelled in this manner (Williams, 1981). In the present case the situation is produced, or at least encouraged, by the turbulent surf conditions in the study area, hence the greater abundance and activity of free-living bacteria than their counterpart attached to detritus particles in the water column (Schleyer, 1981).

Acknowledgements. Financial support for this program by the South African National Committee for Oceanographic Research and the South African Association for Marine Biological Research is gratefully acknowledged.

\section{LITERATURE CITED}

Bell, W. H. (1980). Bacterial utilization of algal extracellular products: the kinetic approach. Limnol. Oceanogr. 25: $1007-1020$

Boney, A. D. (1966). A biology of marine algae. Hutchinson Educational, London

Berry, P. F., Schleyer, M. H. (1983). The brown mussel Perna perna on the Natal coast, South Africa: utilization of available food and energy budget. Mar. Ecol. Prog. Ser 13: 201-210

Craigie, J. S. (1974). Storage products. In: Stewart, W. D. P. 
(ed.) Algal physiology and biochemistry. Blackwell Scientific Publications, Oxford, p. 206-235

Draper, N. R., Smith, H. (1966). Applied regression analysis Wiley, New York

Hellebust, J. A. (1965). Excretion of some organic compounds by marine phytoplankton. Limnol. Oceanogr. 10: 192-206

Hellebust, J. A. (1974). Extracellular products. In: Stewart, W. D. P. (ed.) Algal physiology and biochemistry. Blackwell Scientific Publications, Oxford, p. 838-863

Hobbie, J. E., Crawford, C. C. (1969). Respiration corrections for bacterial uptake of dissolved organic compounds in natural waters. Limnol. Oceanogr. 14: 528-532

Fisher, R. A., Yates, F. (1963). Statistical tables for biological agricultural and medical research, 6th ed. Oliver and Boyd, Edinburgh

Jackson, L. F. (1976). Aspects of the intertidal ecology of the east coast of South Africa. Investl Rep. Oceanogr. Res. Inst. Durban (46): 1-72

James, D. E. (1974). Culturing algae. Carolina Biological Supply Company, Burlington, North Carolina

Lewin, R. A. (1974). Biochemical taxonomy. In: Stewart, W. D. P. (ed.) Algal physiology and biochemistry. Blackwell Scientific Publications, Oxford, p. $1-39$

Milner, H. W. (1961). The chemical composition of algae. In: Burlew, J. S. (ed.) Algal culture from laboratory to pilot plant. Carnegie Institute of Washington, Washington D.C., p. 285-302

Parsons, T. R., Stephens, K., Strickland, J. D. H. (1961). On the chemical composition of eleven species of marine phytoplankters. J. Fish. Res. Bd Can. 18: 1001-1016

Parsons, T. R., Strickland, J. D. H. (1962). On the production of particulate organic carbon by heterotrophic processes in seawater. Deep Sea Res. 8: 211-222

Percival, E., Smestad, B. (1972). Photosynthetic studies on Ulva lactuca. Phytochemistry 11: 1967-1972

Round, F. E. (1965). The biology of the algae. Edward Arnold, London

Schleyer, M. H. (1980a). A preliminary evaluation of hetero- trophic utilisation of a labelled algal extract in a subtidal reef environment. Mar. Ecol. Prog. Ser. 3: 223-229

Schleyer, M. H. (1980b). The role of microorganisms and detritus in the water column of a subtidal reef of Natal, South Africa. Unpublished Ph. D. thesis, University of Natal, Durban

Schleyer, M. H. (1981). Microorganisms and detritus in the water column of a subtidal reef of Natal. Mar. Ecol. Prog. Ser. $4: 307-320$

Segel, I. H. (1975). Enzyme kinetics: behaviour and analysis of rapid equilibrium and steady-state enzyme systems. John Wiley \& Sons, New York

Sieburth, J. M. (1979). Sea microbes. Oxford University Press, New York

Spoehr, H. A., Milner, H. W. (1949). The chemical composition of Chlorella; effect of environmental conditions. PI. Physiol. 24: 120-149

Strickland, J. D. H. (1960). Measuring the production of marine phytoplankton. Bull. Fish. Res. Bd Can. 122: 1-172

Strickland, J. D. H. (1965). Production of organic matter in the primary stages of the marine food chain. In: Riley, J. P., Skirrow, G. (ed.) Chemical oceanography, Vol. 1. Academic Press, London, p. 477-610

Wangersky, P. J. (1978). Production of dissolved organic matter. In: Kinne, O. (ed.) Marine ecology, Vol. IV, Dynamics. John Wiley, Chichester, p. 115-220

Wiebe, W. J., Smith, D. F. (1977). ${ }^{14} \mathrm{C}$-Labelling of the compounds excreted by phytoplankton for employment as a realistic tracer in secondary productivity measurements. Microb. Ecol. 4: 1-8

Williams, P. J. le B. (1981). Incorporation of microheterotrophic processes into the classical paradigm of the planktonic food web. Kieler Meeresforsch. 5: 1-28

Wright, R. T., Hobbie, J. E. (1965). The uptake of organic solutes in lake water. Limnol. Oceanogr. 10 (1): 22-28

Wright, R. T., Hobbie, J. E. (1966). Use of glucose and acetate by bacteria and algae in aquatic ecosystems. Ecology 47 : $447-464$

This paper was submitted to the editor; it was accepted for printing on November 21, 1983 